\title{
Litígio estratégico x litígio estrutural (de interesse público): Ao fim e ao cabo, denominações de um mesmo instituto para a defesa de direitos fundamentais?
}

\author{
Strategic litigation vs. structural litigation (of public interest): After all, names of the \\ same institute for the defense of fundamental rights?
}

\section{Flavianne Fernanda Bitencourt Nóbrega* Eduarda Peixoto da Cunha França*}

\section{RESUMO}

Litígio estratégico e litígio estrutural (de interesse público), ao fim e ao cabo, são denominações de um mesmo instituto para a defesa de direitos fundamentais? Este artigo se propõe a analisar o problema relacionado à confusão conceitual entre esses institutos, a partir do método hipotético-abdutivo de Charles S. Peirce, que possibilita identificar diferenças, com base nos efeitos práticos concebíveis. Para tanto, é realizada uma pesquisa bibliográfico-documental de caráter exploratóriodescritivo sobre a origem, experiência e uso desses institutos, para tornar clara as ideias em torno desses litígios objetos de análise, superando obscuridades conceituais e desenvolvendo um estudo comparado original.

Palavras-chave: Direitos Fundamentais. Litígio Estratégico. Litígio Estrutural.

\section{ABSTRACT}

Strategic litigation and structural litigation, after all, are denominations of the same institute for the protection of fundamental rights? This article aims to analyze the problem related to conceptual confusion between these institutes, based on Charles S. Peirce's hypothetical-abductive method, which makes it possible to identify differences based on believable practical effects. To this end, exploratory-descriptive bibliographic-documental research is carried out on the origin, experience, and use of these institutes, to make clear the ideas surrounding these litigations, overcoming conceptual obscurities, and developing an original comparative study.

Keywords: Fundamental rights. Strategic Litigation. Structural Litigation.

\section{Introdução}

As expressões "litígios estruturais" e "litígio estratégico" têm ganhado espaço no debate brasileiro e internacional, especialmente nas discussões sobre controle jurisdicional de políticas públicas, sendo empregados, não raramente, enquanto sinônimos. Via de regra, são apresentados como temáticas que envolvem a proteção de direitos fundamentais e, em algum grau, a intervenção do Poder Judiciário em estruturas sociais complexas, a fim de protegê-los. Tornar as ideias claras em torno desses conceitos pode obstar que suas más compreensões prejudiquem a defesa de direitos fundamentais, evitando uma aplicação inadequada e desatenta às implicações práticas.

Professora Permanente do Programa de Pós-Graduação em Direito (Mestrado e Doutorado) da UFPE, vinculada à linha de pesquisa “Justiça e Direitos Humanos na América Latina". Professora de Teoria Política e do Estado do Departamento de Direito Público Geral e Processual da UFPE. Coordenadora do Programa de Extensão “Acesso ao Sistema Interamericano de Direitos Humanos - aSIDH" e líder do "Laboratório de Pesquisa em Desenhos Institucionais”, ambos da UFPE. Coordenadora da Câmara de Conciliação, Mediação e Arbitragem (CCMA) da Faculdade de Direito do Recife da UFPE. Pós-doutorado no Max Planck Institute for Comparative and International Private Law - Hamburg. Doutora em Direito pela UFPE, com período sanduíche na Bucerius Law School - Hamburg - Alemanha. Mestre em Ciência Política e Mestre em Direito pela UFPE. E-mail: flavianne@gmail.com

** (1D) Doutoranda e Mestre em Direito pela Universidade Federal de Pernambuco (UFPE). Foi pesquisadora bolsista da Coordenação de Aperfeiçoamento de Pessoal de Nível Superior (CAPES) durante o mestrado. Pesquisadora do NUPID- Núcleo de Pesquisa em Interpretação e Decisão Judicial. E-mail: eduardacunhapf@gmail.com 
O presente artigo busca responder ao seguinte questionamento: litígio estratégico e litígio estrutural (de interesse público)', ao fim e ao cabo, são denominações de um mesmo instituto para a defesa de direitos fundamentais? Para tanto, os litígios em questão serão analisados a partir de seus efeitos práticos concebíveis², fazendo uso do método pragmático hipotético-abdutivo, desenvolvido por Charles S. Peirce em "How to make our ideas clear" (1966). A abdução - também chamada de hipótese por Peirce - é um método científico adequado para tornar claras as ideias e superar possíveis obscuridades e confusões em torno de determinados conceitos (PEIRCE, 2003, p. 232). A escolha justifica-se, portanto, no intuito de eliminar a vagueza que perpassa os debates suscitados acerca dos dois institutos para, assim, extrair contribuições que possam auxiliar no fortalecimento de lutas sociais, que precisam estar alinhadas com estratégias específicas de defesa de direitos fundamentais.

No Brasil, além do preconceito enfrentado por temas que envolvem direitos humanos e fundamentais, as organizações da sociedade civil que se empenham em colocar estes temas na agenda política e, assim, virar a pirâmide de privilégios e exclusões de cabeça para baixo (DORA, 2016, p.11) enfrentam sérias limitações de ordem orçamentária e organizacional, que atrasam, em certa medida, os avanços que poderiam ser obtidos caso estes déficits não existissem. A ponderação entre urgência e impactos de longo prazo (típicos de transformações sociais que envolvem o enfrentamento de problemas multifacetados e arraigados por décadas em sociedades marcadas por extrema desigualdade social) já é uma equação que comporta, naturalmente, variáveis complexas; a indeterminação de conceitos importantes na seara desses direitos, nesse sentido, não pode ser mais uma delas, sob pena de causar ainda mais prejuízos irreversíveis às vítimas.

A pesquisa apresenta, dessa forma, uma proposta inovadora, que não só leva conceitos a sério, mas preocupase, primeiramente, com os efeitos práticos que sua delimitação precisa e correta pode gerar nas lutas por mais igualdade social e empoderamento daqueles que não têm vez e voz na agenda política. O método comparativo no direito (ZWEIGERT; KÖTZ, 1992) também foi utilizado no presente estudo, com o intuito de subsidiar, cientificamente, a busca por semelhanças e diferenças entre os litígios em questão. Dois objetos só podem ser estudados de forma comparada se, aos menos, partilham uma característica comum (MÜLLER-CHEN, et al., 2015, p. 425-426). Neste trabalho, os direitos fundamentais se sobressaem como denominador comum entre os litígios estruturais e o litígio estratégico para justificar a pesquisa comparada. Ao final, a partir da máxima pragmatista - que parte dos efeitos práticos de um determinado objeto para, a partir de então, conceber o seu significado (PEIRCE, 1966, p.15) - visa-se preencher as lacunas doutrinárias existentes nos campos do Direito que mais se debruçam sobre essas temáticas, quais sejam: o Direito Constitucional e o Direito Processual Civil.

A estrutura do trabalho foi construída em três partes. A primeira explorou o conceito de litígio estratégico, com o intuito de entender: a) o que é litígio estratégico; b) a diferença entre litígio estratégico e litígio comum; e c) por que e quando litigar estrategicamente. A segunda, por sua vez, investigou o que são litígios estruturais (de interesse público), averiguando: a) seu conceito e características principais; b) sua origem com a decisão da Suprema Corte dos Estados Unidos em Brown v. Board of Education; c) a diferença entre ações individuais e litígios estruturais. Ainda nesta oportunidade, os litígios estratégicos e estruturais foram comparados, com o intuito de entender se, de fato, são semelhantes ou diferentes (e em que medida o são). Na terceira e última parte, por fim, analisou-se como tornar as ideias claras acerca dos litígios em questão pode contribuir com a de defesa de direitos fundamentais, afinal, investigar litígios estruturais e estratégicos significa, em maior ou menor grau - a depender da ênfase aplicada -, estudar o sistema de justiça, as instâncias majoritárias, a sociedade civil organizada e, sobretudo, um ponto capaz de traduzir os direitos fundamentais em realidade: as políticas públicas.

A imbricação das referidas temáticas insere o presente trabalho em um debate mais amplo e multifacetado, que não só dá ensejo a novas frentes de estudo, como, também, revisita embates antigos, sendo o controle jurisdicional de políticas públicas - bem como as objeções apresentadas acerca do judicial review - um destes. A possibilidade de obter mudanças sociais através do Poder Judiciário traz a necessidade de uma releitura do papel

O recorte acerca da característica "de interesse público" - que aparece enquanto adjetivo dos litígios estruturais - justifica-se em virtude de nem todos os litígios estruturais serem, de fato, de interesse público, havendo a possibilidade de que figurem enquanto litígios policêntricos que envolvem, primordialmente, interesses privados, a exemplo do processo de recuperação judicial de empresas (VITORELLI, 2018, p.12-13). O acréscimo, dessa forma, busca deixar explícito que o presente estudo não estende sua investigação a conflitos que envolvem interesses privados. Levar conceitos a sério, nesse sentido, pode evitar o desperdício de futuros esforços e debates acadêmicos cujo escopo seja o de discutir aspectos pontuais de litígios estruturais de interesse público e de interesse privado, dando a oportunidade de que, desde já, as pesquisas sejam melhor direcionadas.

2 Método pragmático de Peirce “(...) considera quais os efeitos, que podem ter certos comportamentos práticos, que concebemos que o objeto da nossa concepção tem. A nossa concepção dos seus efeitos constitui o conjunto da nossa concepção do objeto.” (PEIRCE, 1966, p.13). 
exercido pela jurisdição em sua feição tradicional de dispute resolution (FISS, 2003, p. 51) e o entendimento de que o processo pode ter efeitos diversos e com maior repercussão no espaço social, saindo de sua lógica clássica.

\section{Litígio estratégico: Conceito e características}

A partir da redemocratização dos países latino-americanos, na segunda metade do século $\mathrm{XX}$, algumas organizações da sociedade civil adotaram a litigância estratégica como ferramenta para fortalecer as lutas pela ampliação de direitos, sobretudo dos direitos fundamentais, interagindo com o que denomina-se de judicialização das relações sociais. O litígio estratégico consiste numa prática voltada para a transformação da realidade social, tendo como escopo veicular temas constitucionais aos quais não foi dado o devido tratamento pelo poder público, buscando conferir visibilidade ao objeto de reivindicação e alcançar o reconhecimento ou a ampliação do conteúdo do direito pelas vias ordinárias próprias. Utiliza o Poder Judiciário como locus de deliberação política e convida os demais atores constitucionais, juntamente com a sociedade, ao diálogo.

Através de Casos emblemáticos, escolhidos estrategicamente por grupos da sociedade organizada (que buscam ver seu direito reconhecido), provoca-se a atividade jurisdicional do Estado com o intuito de alcançar um efeito significativo nas políticas públicas, na legislação e/ou na sociedade. Gera, dessa forma, um impacto no sistema de justiça em geral a partir de um caso concreto e possibilita a interferência de uma ampla gama de atores no processo, uma vez que as demandas são de interesse público. Entende-se, dessa forma, ser uma prática voltada a tutelar direitos fundamentais e reivindicar a reorganização de instituições que provocam violações aos direitos dos indivíduos em virtude de falhas estruturais e da má performance no exercício de suas atribuições.

Sumariamente, a prática resume-se a: 1) primeiramente, escolhe-se um caso de alto impacto, cujo direito violado, geralmente, tem cariz coletiva; 2) posteriormente, judicializa-se de forma estratégica o caso em questão, apostando no valor simbólico do Poder Judiciário enquanto arena de deliberação e na tomada de decisões cujos impactos transcendam os efeitos inter-partes e criem precedentes para casos similares; 3) por fim, aguarda-se uma sentença que atenda aos objetivos esperados, que oscilam a depender da demanda, podendo variar entre: formulação ou reforma de políticas públicas; reformas legais; conscientização social; empoderamento de grupos vulnerabilizados; denunciação de violações massivas de direitos fundamentais, entre outros. O litígio estratégico gera, dessa forma, um impacto no sistema de justiça em geral a partir de um caso concreto e possibilita a interferência de uma ampla gama de atores no processo, uma vez que as demandas são de interesse público.

O diferencial, que permite categorizar o litígio enquanto "estratégico", decorre do fato de que a judicialização do caso emblemático nem sempre almeja, necessariamente, a vitória associada à procedência total do pedido. Nesses casos, a provocação judicial já pode ser considerada bem-sucedida quando o assunto venha a produzir algum tipo de impacto na sociedade, independentemente de acolhimento da pretensão pelo Judiciário. Ou seja: é estratégico porque objetiva, primariamente, impulsionar o diálogo acerca do tema controvertido e, circunstancialmente, refletir no direito positivo uma nova visão de mundo (VALLE, 2016, p. 23).

Assim, num primeiro momento, o strategic litigation redireciona determinadas reivindicações sociais (sobretudo aquelas de elevado desacordo moral) para o Judiciário, a fim de que este atue enquanto um agente articulador do debate público para, num segundo momento, devolver o debate aos canais democráticos. Entende-se, portanto, que o papel desempenhado pelos juízes nesse cenário é o de catalisar pautas que não estão recebendo o devido tratamento pelo Poder Público. Afinal, não raramente, por questões de conveniência, dificuldades operacionais e/ou orçamentárias, ou, ainda, por falta de consenso para a formação da maioria necessária à deliberação específica, as instâncias políticas preferem assumir o custo da inércia ao invés do ônus da deliberação, por acreditarem que aquele é mais vantajoso que este.

Ainda acerca de suas características, vale salientar que essa ferramenta pode ser utilizada de maneira preventiva ou corretiva. Na primeira, é utilizada como uma medida de precaução para prevenir ou evitar danos contra os direitos humanos, especialmente quando não existem dados científicos que comprovem as consequências de uma determinada ação. A maneira repressiva, por sua vez, é utilizada como veículo corretivo, ou seja, quando uma determinada violação a direitos humanos já existe e o que se busca é a reparação integral pelo dano causado. Não obstante a existência desse instituto nas duas modalidades apresentadas, frisa-se que, até quando utilizado de maneira repressiva, o litígio estratégico visa reparar não só a lesão ocorrida no passado, mas, também, eliminar a ameaça contínua a direitos fundamentais. 
Explora, portanto, a interação entre cidadãos e agentes políticos e constitucionais, trazendo para o cotidiano da vida coletiva a luta pela aplicação do Texto texto constitucional. Aposta na mobilização dos cidadãos e dos movimentos sociais para a transformação da realidade social e permite a incorporação de grupos vulnerabilizados no debate constitucional.

\subsection{Diferenciação de litígio comum para o litígio estratégico}

É importante que haja uma delimitação das hipóteses de utilização do litígio estratégico, a fim de evitar a falsa impressão de que sua prática pode ser aplicada de qualquer forma e a qualquer caso, o que contribuiria para a má compreensão e vulgarização do instituto, prejudicando o pleno desenvolvimento de suas potencialidades. Essa ferramenta não deve ser utilizada em casos que podem ser decididos através de uma decisão judicial simples, mas, tão somente, quando se estiver diante de demandas complexas - sobretudo aquelas de cariz estruturante -, que por sua natureza, envolvem diversas variáveis e requerem a atuação de uma ampla gama de atores sociais. São demandas de interesse público, que clamam por mudanças complexas, gradativas e prolongadas, tornando o trâmite do processo judicial ainda mais demorado e caro.

Classifica-se, portanto, como uma ação de proteção social, embora nem toda ação de proteção social possa ser considerada litígio estratégico, pois este foca no avanço político-jurídico de um tema constitucional que interessa a determinados grupos sociais, atuando no exercício de campanhas de mobilização de cunho educativo e persuasivo em torno dos direitos colocados em pauta. Por isso a intervenção judicial individual, em favor de um jurisdicionado "X", não é capaz de apontar os equívocos do agir administrativo. O cunho transformativo buscado pelo litígio estratégico - de efeito corretivo da matriz de ação, extensível para outras situações individuais - só se mostra possível a partir de uma intervenção estrutural no modo de agir da Administração, que só é viável em casos emblemáticos (BRINKS; FORBATH, 2010, p. 1945), capazes de denunciar um quadro de violação massiva a direitos fundamentais.

Dessa forma, não obstante a existência de outros mecanismos e instrumentos de proteção social, as ações individuais, na grande maioria das vezes, não colocam em questão tão acentuadamente conteúdos de incidência política que normalmente são estruturais (BRINKS; FORBATH, 2010, p. 1950), enquanto casos emblemáticos, por sua vez, permitem a fixação de posições, a reversão de determinados precedentes dos tribunais, e o rompimento de paradigmas, alcançando soluções coletivas e, muitas vezes, estruturantes.

As chances de concretização de direitos de cunho coletivo, dessa forma, tais quais os direitos socioeconômicos, são maiores com o litígio estratégico, pois as providências necessárias para a transformação social, em geral, envolvem realidades revestidas de alta complexidade, cujo enfrentamento exige engenho e arte, bem como significativos recursos.

Não obstante o importante papel desempenhado pelo Poder Judiciário nesse processo, destaca-se também a relevância da atuação dos advogados que, buscando alcançar soluções alternativas de disputa, enxergam na mídia ferramentas e apostam na jurisdição constitucional como caminho frutífero para alcançar as transformações almejadas. Dessa forma, os advogados que litigam nessa seara devem ser capazes de identificar as antinomias e lacunas do ordenamento jurídico interno e encontrar soluções que ultrapassem a fronteira do direito positivo.

O litígio estratégico não utiliza-se da advocacia client-oriented, própria de demandas individuais; utiliza-se da advocacia issue-oriented, voltada para o avanço político-jurídico de um tema constitucional de interesse de um determinado grupo social, que atua no exercício de campanhas de cunho persuasivo em torno de um determinado tema de direitos fundamentais (CARDOSO, 2011, p. 41-42). Nesse sentido, o litígio estratégico também apresenta um potencial informativo e de sensibilização da sociedade em geral.

\subsection{Por que e quando litigar estrategicamente?}

A importância de litigar estrategicamente pode ser percebida quando observa-se que, no espaço público, muitos indivíduos reivindicam seus direitos, mas essas reivindicações não são organizadas, estruturadas, e muito menos judicializadas ou pendentes de reforma legislativa. O litígio estratégico, por sua vez, traz esses pleitos à pauta pública, rememorando os atores constitucionais de seus papéis e funções na concretização dos compromissos constitucionais. Problemas sociais prescindem da intervenção de várias entidades, num conjunto complexo e coordenado de ações. É importante pois combate a invisibilidade de determinadas questões sociais e opera em favor da democracia e da efetivação de direitos fundamentais. 
Não é utilizado para todo e qualquer caso de forma indistinta, pois nem todos prescindem desse tipo de ferramenta para alcançar o pleito pretendido. Deve ser reservado para situações graves, sendo necessário ter em mente o que objetiva-se com a prática desse instituto, pois seus propósitos são variáveis e vão desde uma reforma legal ou modificação/criação de políticas públicas, até à criação uma cultura de direitos humanos que ajude na construção de um verdadeiro Estado de Democrático de Direito. Assim, antes de dar início ao processo, é interessante que reflita-se acerca: 1) dos objetivos a serem perseguidos; 2) da viabilidade do caso escolhido ocasionar os impactos desejados (o caso precisa ser de interesse público, denunciar falhas estruturais do Estado e ter potencial de provocar consequências positivas); 3) do tipo de recurso a ser utilizado; 4) do posicionamento dos juízes em torno do direito sobre o qual versa o litígio (DUQUE, 2014. p. 45).

É importante que a academia brasileira debata o litígio estratégico a fim de que advogados e grupos sociais conheçam melhor os alcances desse instituto e utilizem-se dessa ferramenta a fim de entender quais demandas relativas aos direitos fundamentais podem ser exploradas e trabalhadas nesse tipo de litígio. É um meio inovador e promissor de dar visibilidade a questões que não estão recebendo o devido tratamento pelo poder público, confiando no potencial transformador do direito para mudar a realidade social. De sua utilização, pode-se obter como resultados: o despertar de novas consciências, o empoderamento de grupos e movimentos sociais, a inclusão de temas nas agendas públicas que, num primeiro momento, não eram priorizadas, e o fortalecimento substancial dos direitos humanos e fundamentais.

\section{Litígio estrutural (de interesse público): Conceito e características}

Para Fiss (1979, p. 30), no julgamento de Brown v. Board of Education, emergiu uma nova forma de adjudicação, denominada de "reforma estrutural" (structural reform). Brown era um caso de interesse público cujo pleito central se voltava à cessação da segregação étnica nas escolas públicas dos Estados Unidos, em larga medida autorizada pela doutrina do "separados, porém iguais" (separate but equal), sustentada pela Suprema Corte do país em 1896 no caso "Plessy v. Ferguson" (JOBIM, 2017, p. 563). A referida doutrina sustentava que o simples fato de segregar - ou seja, de não permitir que os negros frequentassem os mesmos locais que os brancos - não feriria o direito à igualdade, desde que todos possuíssem acesso a serviços públicos da mesma qualidade. Na prática, existiam consideráveis diferenças entre os serviços oferecidos aos brancos e aos negros, sobretudo nos estados do sul do país.

O caso foi julgado em 17 de maio de 1954 pela Suprema Corte do país, que reconheceu que a segregação racial em escolas era inconstitucional por violar à $14^{\mathrm{a}}$ emenda da Constituição norte-americana. As técnicas utilizadas pela Corte permitiram o surgimento da structural injunctions, um modelo de adjudicação pelo qual o Poder Judiciário determina que autoridades políticas ou administrativas formulem políticas públicas voltadas à

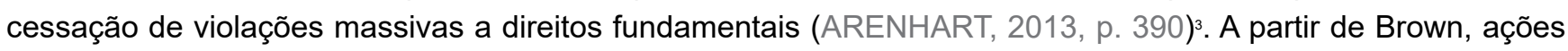
semelhantes foram ajuizadas com o intuito de corrigir falhas nas políticas públicas do país que envolviam, por exemplo, o tratamento de pessoas com doenças mentais, as condições degradantes no sistema prisional dos Estados Unidos, as sistemáticas violações aos direitos dos indivíduos em detrimento dos abusos cometidos por agentes policiais e a segregação chancelada pelos estados na política oficial de moradia (WEAVER, 2004, p. 1617).

O entendimento completo do que seriam os "litígios estruturais" (de interesse público) - sendo aqui conceituados enquanto falhas sistêmicas que violam massivamente direitos fundamentais e que podem decorrer diretamente da ação ou omissão de instituições públicas ou privadas bem como de problemáticas arraigadas numa determinada localidade em virtude de questões culturais, históricas e sociais - exige uma explicação mais complexa que a de litígio estratégico. Isso porque a temática desdobra-se em denominações que são facilmente confundidas.

O primeiro conceito importante à compreensão dos litígios estruturais (de interesse público) é o de "Adjudicação", que consiste no "processo social por meio do qual os juízes dão significado aos valores públicos" (FISS, 1979, p. 30).

\footnotetext{
É certo que a superação de uma doutrina enraizada na cultura do país não seria simples e demandaria uma série de medidas a serem realizadas a longo prazo, bem como a reestruturação do sistema público de ensino como um todo, de forma que apesar de ter reconhecido o direito de crianças negras receberem educação igual à oferecida a crianças brancas, a decisão não fixou como esse objetivo deveria ser concretizado. Foi somente com o julgamento de outra ação, denominada Brown II, que restou determinado que os tribunais regionais "disporiam de amplos poderes de equity para alcançar o desiderato de afastar a segregação das escolas na prática, desenvolvendo e impondo políticas públicas para tanto e dispondo de recursos financeiros para tal" (DALLA; CÔRTES, 2014, p.234).
} 
O termo "adjudication" é usual na literatura de língua inglesa para designar a atividade realizada pelo Judiciário na solução de conflitos. No brasil, o termo é mais utilizado nas relações de posse e propriedade (a exemplo da adjudicação compulsória), mas a sua extensão para o mesmo sentido utilizado na língua inglesa é correta. O juiz, ao decidir um determinado caso, aplica a norma ao caso concreto adjudicando - ou seja, atribuindo - uma solução, entre outras possíveis, para a controvérsia em questão.

A reforma estrutural, por sua vez, é um tipo de adjudicação, cujos caracteres distintivos são a natureza constitucional dos valores públicos discutidos e o específico escopo do juiz é o de tentar dar significado concreto aos valores constitucionais através da reestruturação de burocracias estatais (FISS, 1979, p. 8). Ao dispor acerca desse conceito, o autor parte da premissa de que a operacionalidade de grandes organizações - e não apenas atos isolados de indivíduos dentro ou fora dessas estruturas - podem afetar a vida social de diversas maneiras e que, em determinadas ocasiões, direitos fundamentais não podem ser adequadamente assegurados sem que haja uma intervenção direta em arranjos institucionais (FISS, 1979, p. 9). A definição apresentada pelo autor, dessa forma, encontra-se amplamente relacionada àqueles litígios estruturais que são de interesse público.

O processo judicial de caráter estrutural é "aquele no qual o juiz, enfrentando uma burocracia estatal no que tange aos valores de âmbito constitucional, incumbe-se de reestruturar a organização para eliminar a ameaça imposta a tais valores pelos arranjos institucionais existentes" (FISS, 1979, p. 9). A morfologia do processo estrutural, ainda nesse sentido, pode ser definida da seguinte forma: 1) estrutura policêntrica das partes; 2) preocupação prospectiva da tutela; 3) objeto do processo construído pelas partes e pelo juiz; 4) participação contínua da corte no processo de desenvolvimento e implementação da medida. Seu enfoque, nesse seguimento, se desloca da reparação de violação pontual do direito à reestruturação do estado de coisas transgressivo.A função dos processos estruturais é a de desestabilizar o status quo, operando como um marco inicial na direção de um novo estado de coisas, trazendo à público o debate sobre a violação de direitos existente e gerando o empoderamento da sociedade envolvida no litígio com a prolação da decisão estrutural.

As injunctions - que não possuem um correspondente exato no sistema brasileiro, mas podem ser traduzidas como "medidas estruturantes" - é o meio pelo qual essas diretivas de reconstrução são transmitidas (FISS, 1979 , p. 19). No direito norte-americano, ela consiste em uma medida judicial que proíbe o réu de praticar ou determina que ele pratique determinado ato. Usualmente, tal medida judicial possui um caráter preventivo, visto que não se destina somente à reparação de ilícitos passados, mas a evitar danos futuros (FISS, 1979, p. 19).

Assim, enquanto litigar estrategicamente é uma ação, o litígio estrutural é um objeto de adjudicação, proveniente de uma realidade concreta. Em geral, apesar da denominação ser utilizada para descrever problemas de caráter público, litígios estruturais não restringem-se à esta esfera, possuindo, também, desdobramentos na esfera privada. O presente trabalho, entretanto, fará menção somente aos "litígios estruturais" de interesse público, pois entendese que somente quando assume esta característica é que possui pontos em comum com o "litígio estratégico".

\subsection{Diferenças práticas entre litígio estrutural e litígio comum}

Os litígios estruturais surgem como resposta à insuficiência da tutela jurisdicional individual, procurando reestruturar determinada organização social ou política pública e concretizar, consequentemente, direitos e interesses socialmente relevantes. Funcionam, por exemplo, invertendo a lógica presente na jurisdição brasileira: priorizam o provimento coletivo e o interesse público, contrapondo-se a uma tutela individual e privada (FACHIN; SCHINEMANN, 2018, p. 225).

Uma ação civil, a priori, é pensada como uma controvérsia privada entre autor e réu, de forma que a arquitetura jurídica é formulada a partir de dois interesses unitários, diametralmente opostos, a serem decididos a partir de uma lógica na qual "o vencedor leva tudo" (ROACH, 1976, p. 1282). Não obstante a existência da possibilidade de terceiros interferirem no processo a fim de protegerem seus interesses, tais interseções são uma verdadeira exceção à regra, tratadas pelas cortes e partes como algo, até mesmo, indesejado (SHAPIRO, 1968, p. 721). A base desse modelo é o pensamento de linhas individualistas e patrimonialistas, na qual vigoram os princípios da liberdade, propriedade privada e segurança jurídica (MITIDIERO, 2010, p. 182), entendendo o procedimento civil como mero assunto privado entre as partes (VENTURI, 2007, p. 27).

A adjudicação, dessa forma, é pensada com o intuito de administração e disposição de patrimônio individual, despreocupada com a tutela de ordem social e metaindividual (MITIDIERO, 2010, p. 184). Esse tipo de raciocínio cultiva uma abstração polarizada das relações sociais e pressupõe que os interesses das partes são diametralmente 
opostos, que é necessário decretar um "vencedor" e um "perdedor" e que os interesses possíveis de consideração são somente aqueles trazidos ao processo.

Ao se tratar de uma demanda que envolve políticas públicas, entretanto, adentra-se no risco de ignorar os interesses adjacentes (de terceiros e do próprio Estado enquanto conjunto) e criar consideráveis contradições entre diversas decisões. Ainda que se trate de uma demanda coletiva, é necessário que ela não seja uma mera declaração da "vitória" de uma coletividade vencedora em face do Estado, a fim de que haja uma efetiva tutela dos direitos provenientes de litígios estruturais de interesse público.

Um clássico exemplo que ajuda a entender a temática de forma prática é a judicialização da saúde. Tem-se, no Brasil, milhares de decisões individuais que, somadas, representam um considerável impacto na alocação de recursos do Estad (BARROSO, 2010, p. 37). Dados de julho de 2017, em matéria publicada pela Folha de São Paulo, demonstram que, dentre 118,6 mil decisões que condenaram o estado ao fornecimento de medicamentos, apenas 474 foram descumpridas, denotando um baixíssimo índice de descumprimento e revelando uma atuação (FACHIN; SCHINEMANN, 2018, p. 140), talvez, pouco criteriosa na adjudicação de direitos prestacionais face ao Estado, que não considera, sobretudo, dois aspectos negativos: a) o impacto econômico da concessão de provimentos prestacionais; b) a falta de capacidade da medida de realmente resolver o problema da saúde no país; c) a violação ao princípio da igualdade, uma vez que, não obstante a situação do autor da demanda ser semelhante a de outros indivíduos, somente aquele que judicializou terá a oportunidade de ver o seu direito tutelado.

Entende-se que a tomada de medidas paliativas e particularizadas, que preocupam-se apenas em combater as consequências das violações estruturais, são incapazes de sanar as verdadeiras causas do problema. Nesse sentido, apresenta-se o processo judicial estrutural de interesse público enquanto ferramenta disponível tanto ao magistrado, como aos legitimados para a proposição de ações coletivas, entendendo-se este como "aquele no qual o juiz, enfrentando uma burocracia estatal no que tange aos valores de âmbito constitucional, incumbe-se de reestruturar a organização para eliminar a ameaça imposta a tais valores pelos arranjos institucionais existentes" (FISS, 1979, p. 9).

Enquanto, dessa forma, as ações individuais restringem-se a reparar o dano sofrido por uma das partes processuais, os processos estruturais, que tratam de litígios estruturais de interesse público, têm um caráter prospectivo. Ademais, enquanto as primeiras restringem-se a proteger o direito de um só indivíduo - aquele que possui acesso à informação e condições necessárias para arcar com os custos e morosidade processual -, os segundos buscam tutelar o direito da coletividade e desenhar, remodelar ou implementar políticas públicas, que beneficiam a coletividade como um todo.

Alguns pontos centrais acerca dos litígios estruturais, dessa forma, são: 1) as violações de direitos não são pontuais e isoladas - são dinâmicas e estão em curso - ; 2) os indivíduos cujos direitos estão sendo violados podem não fazer parte do processo judicial diretamente, mas serão afetados pelas consequências da sentença; 3 ) o centro de preocupação desse tipo de problema não são condutas específicas que inobservaram direitos, mas o próprio contexto em que acontecem; 4) mais importante que determinar quem é responsável pela atuação/omissão que viola direitos é pensar em como a situação pode ser resolvida e como os esforços para que isso aconteça podem ser subdivididos (na hipótese de haver mais de uma instituição que esteja causando o dano/violação); 5) a reparação do dano não ocorre pela simples concessão (no caso do pleito ser julgado procedente) de uma determinada prestação, pois a causalidade do problema é complexa, sendo necessário que, de fato, o juiz exerça um papel de articulador e mediador a fim de que o problema possa ser resolvido.

\section{Como tornar clara a diferenciação entre litígio estratégico e litígios estruturais (de interesse público) pode, na prática, contribuir para a defesa de direitos fundamentais?}

A partir da exposição acerca das características e conceitos dos litígios em questão, obteve-se o resultado de que litígios estruturais de interesse público e litígio estratégico são diferentes. Isso porque enquanto o primeiro é um problema complexo, arraigado e que demanda, para a sua solução, o desenho, ajuste ou implementação de uma política pública, o segundo é um tipo de litigância que visa a superação de um determinado estado de coisas violador de direitos fundamentais através da judicialização de um caso emblemático.

Conhecer as peculiaridades dos institutos em questão, através do método pragmático aplicado ao direito (NÓBREGA, 2007, p. 58) pode contribuir na defesa de direitos fundamentais pois: a) um manejo adequado e 
consciente de litígios estruturais pode colaborar para mitigar a litigância errática e individualizada de problemas sociais e, consequentemente, dar enfoque à tutela coletiva; b) a percepção da complexidade e policentria dos litígios estruturais denuncia falhas nas políticas públicas e possíveis omissões das instâncias majoritárias em ajustá-las ou inércia em implementá-las; c) o enfrentamento de litígios estruturais, por mais custoso que possa parecer em um primeiro momento, cumpre com o escopo da Constituição de 1988 no sentido de buscar que transformações sociais saiam do papel; d) a litigância estratégica pode ser ensejo a uma sentença judicial com efeitos materiais, simbólicos, diretos ou indiretos (RODRÍGUEZ; FRANCO, 2010, p. 15); e) a utilização de casos paradigmáticos para tentar causar uma mudança na jurisprudência ou políticas públicas pode chamar a atenção para um problema grave que, anteriormente, era imperceptível ou negligenciado pela população, contribuindo para um melhor direcionamento nas lutas sociais; f) o problema judicializado estrategicamente pode transformar-se em um "problema de direitos humanos" e, portanto, ser observado com mais cautela pelas instâncias majoritárias, pela sociedade como um todo e ter repercussões internacionais - como, por exemplo, um ajuizamento de demanda na Corte Interamericana de Direitos Humanos, o que daria um destaque ainda maior ao problema em questão -; g) a litigância estratégica é uma ferramenta capaz de empoderar a sociedade civil para que esta demande a consolidação de seus direitos, sobretudo tendo em vista que os violadores de direitos fundamentais estão "cada vez mais bem assessorados por advogados e preparados para encabeçar o conflito em várias frentes" (ARAÚJO, 2016, p. 8).

Ainda nesse sentido, vale ressaltar que a prática de litigância estratégica para denunciar litígios estruturais pode ser uma técnica importante na superação de problemas que violam - massiva e reiteradamente - direitos fundamentais. Saber quais são as características dos litígios estruturais é importante para poder descrever sua complexidade e desdobramentos em petições iniciais a fim de demonstrar ao juiz que o problema em questão é urgente e precisa ser tratado, bem como para que juristas e acadêmicos interessados na temática direcionem seus esforços no sentido de produzir pesquisas voltadas ao reconhecimento, denúncia, identificação de consequências e possíveis soluções que podem ser adotadas a fim de superá-lo. Em contrapartida, estudar o momento correto, as condições institucionais e políticas favoráveis, bem como o caso emblemático que pode, de fato, impactar a ótica pela qual uma situação que viola direitos fundamentais vem sendo enfrentada, pode ser decisivo na superação de falhas estruturais e na provocação de avanços que poderiam não ser obtidos durante anos, caso continuassem a depender do interesse das instâncias políticas.

Os pontos acima expostos não olvidam do fato de que ambos os os institutos parecem apostar demasiadamente no papel do Poder Judiciário, sendo necessário que este possua um grau considerável de independência e acessibilidade para que litigâncias estratégicas tenham seu pleito atendido e litígios estruturais sejam, de fato, resolvidos através de sentenças. A temática do controle jurisdicional de políticas públicas, como sustentado anteriormente, está sempre em pauta nas discussões doutrinárias e acadêmicas que perpassam os litígios objetos de estudo4.

Assim, não raramente, decisões judiciais tornaram-se capazes de antecipar questões que deveriam receber soluções coletivas pelas vias legislativas, relegando os procedimentos parlamentares tendentes à tomada de decisões públicas, os quais, visto demandarem a formação de maiorias cuja composição não é singela, são, necessariamente, mais vagarosos (FONTE, 2017, p. 34). Logo, diante dos desvios aos quais o processo político está sujeito, cortes possuem, de fato, a prerrogativa de funcionarem como canalizadoras e catalisadoras de importantes debates envolvendo a proteção de direitos fundamentais de grupos ditos "vulnerabilizados".

Vale a ressalva, entretanto, de que a eficiência do processo (o seu êxito), bem como as expectativas que são criadas em torno dele, não devem partir de maximizações irrealistas, mas de análises pragmáticas da conjuntura sócio-política em que se insere. Tanto o ato de litigar estrategicamente quanto a superação de litígios estruturais envolvem, imprescindivelmente, práticas políticas - visto implicarem, quase sempre, em escolhas trágicas no direcionamento de orçamento público - sendo necessário considerar não apenas o papel que o juiz exerce no procedimento, mas também o papel de todos os envolvidos direta ou indiretamente no caso sub judice.

Dessa forma, o enfrentamento de litígios estruturais por meio de litigância estratégica tem o potencial de fomentar práticas dialógicas entre os Poderes e a sociedade civil organizada, uma vez que a complexidade de problemas policêntricos, na maioria das vezes, denota a necessidade de atuações coparticipativas, não sendo

4 No Brasil, isso ocorre, sobretudo, pela: a) possibilidade de submeter qualquer questão ao Poder Judiciário devido à cláusula do acesso à justiça; b) expansão do rol de legitimados para provocar a jurisdição constitucional concentrada, bem como a tutela coletiva de direitos - manejada pelo Ministério Público e outros atores constitucionais legitimados - ; c) a possibilidade de que todos os juízes - mesmo os de primeiro grau - realizem o controle de constitucionalidade das normas e atos administrativos; d) o fato da Constituição de 1988 ter estabelecido normas programáticas e abertas, deixando uma certa margem de discricionariedade a quem as interpreta (FONTE, 2017, p.34). 
suficiente a prestação jurisdicional isolada. Assim, tribunais podem desempenhar um papel catalisador em cenários de bloqueios institucionais (VALLE, 2016, p.15), fazendo com que problemas antes negligenciados passem a ser problemas considerados urgentes, sobretudo por envolverem violações massivas a direitos fundamentais.

Depois do pontapé inicial, todavia, é necessário que os juízes busquem abrir espaço para a atuação dos Poderes Executivo e Legislativo, bem como para a sociedade civil organizada, por meio, por exemplo, de audiências públicas e do instituto do amicus curiae (ALMEIDA, 2019, p. 700). É o que denomina-se de "ativismo dialógico" (RODRÍGUEZ, 2016, p. 15), postura judicial mais atenta às consequências da decisão e à necessidade de inserção, no processo, de atores indispensáveis às transformações sociais, tendo em vista a insuficiência do direito e da atividade judicial solipsista para tratar de questões que envolvem políticas públicas. Essa codependência e ciência de que da tarefa de guarda da Constituição é uma responsabilidade de todos (FISHER, 1988, p. 23), pode trazer resultados e transformações sociais em menor tempo e de forma mais precisa, uma vez que cada participante atuaria conforme a sua expertise.

Ademais, a litigância em âmbito judicial pode oferecer melhores resultados quando articulada com outras táticas políticas, sendo compreendida como parte de uma estratégia coordenada que ganha sentido, sobretudo, fora do sistema de justiça, em espaços societários que precisam ser fortalecidos (OSORIO, 2019, p. 587). As ações dos tribunais, dessa forma, são “(...) apenas um dos muitos tipos diferentes de recursos e constrangimentos que moldam os termos das lutas de poder entre grupos em conflitos" (MCCANN, 1994, p. 13). O desafio para a sociedade civil e para as entidades do sistema de justiça - que atuam junto aos poderes Executivo, Legislativo e Judiciário - é definir o melhor conjunto de ferramentas capazes maximizar resultados na seara dos direitos sociais, econômicos e culturais - inclusive na fase pré-processual. Sob outro enfoque, a questão reside em saber como a politização da lei e do Judiciário nas democracias contemporâneas pode contribuir para que o litígio e a mobilização por direitos sejam, além de uma ferramenta legal, uma ferramenta política para a mudança social.

Não existem remédios milagrosos que permitam a uma corte, um tribunal ou a um juiz de primeira instância, por exemplo, transformar a realidade através de uma atuação monocrática - nem quando essa demanda chega por meio de uma litigância estratégica ou através da prolação de uma sentença que denuncie litígios estruturais de interesse público - , sobretudo tendo em vista que a concretização de direitos fundamentais exige um procedimento contínuo de aprimoramento que envolve tanto o sistema de justiça, quanto às instâncias majoritárias e a sociedade civil organizada. Transformações sociais só são viáveis através de esforços compartilhados entre uma ampla gama de atores, sem os quais a decisão judicial, muito provavelmente, teria um cunho meramente declaratório.

\section{Conclusão}

O presente trabalho teve como escopo tornar claras as ideias acerca dos conceitos de litígios estruturais de interesse público e litígio estratégico, buscando investigar, ademais, as implicações práticas dessa distinção a fim de compreender como os referidos institutos podem contribuir com a defesa de direitos fundamentais. Assim, as duas primeiras etapas do trabalho foram destinadas à delimitação dos conceitos, análise dos desdobramentos e mapeamento das peculiaridades dos litígios em questão. Superada a indeterminação acerca da temática, foi observado e explicitado como os litígios objeto de estudo podem contribuir com as discussões que envolvem os direitos fundamentais ou com a própria defesa destes.

Assim, observou-se que o litígio estrutural de interesse público e o litígio estratégico, a partir do estudo comparado desenvolvido, com base no método pragmático, são diferentes. A análise comparada pressupõe um ponto em comum para ser justificada (MÜLLER-CHEN et al., 2015, p. 425-426), de forma que, no início da pesquisa, justificou-se a comparação no fato de que ambos os litígios estão relacionados a um estado de coisas violador de direitos fundamentais, o que foi confirmado e ratificado ao final do estudo.

As políticas públicas e o Poder Judiciário também aparecem, na maioria das vezes, enquanto pontos de intersecção entre os referidos litígios, mas nem sempre um litígio estrutural de interesse público será judicializado e resolvido por meio de uma sentença estrutural (é possível que ele seja resolvido espontaneamente, por exemplo, pela Administração Pública e/ou pelo Poder Legislativo) e nem sempre um litígio estratégico visará a revisão ou implementação de políticas públicas (pois pode objetivar, também, uma mudança de jurisprudência ou um aprimoramento da legislação). 
Da análise, chegou-se à conclusão de que: o litígio estratégico consiste no ato de judicializar uma determinada demanda a fim de obter uma mudança na realidade social; enquanto que os litígios estruturais consistem no problema que se pretende transpor, podendo, se judicializado, dar ensejo a um processo estrutural no qual o Judiciário poderá determinar medidas estruturantes, caso este esteja disposto a dar andamento à demanda.

Afinal, cenários nos quais os juízes decidem pela adoção de posturas autocontidas ou deferentes não podem ser descartados, tendo em vista que as variáveis inerentes - em maior ou menor grau - ao processo estrutural de interesse público (tais quais: a complexidade, a demora, o custo operacional e a (in)disponibilidade dos atores envolvidos de dialogarem para chegar a um consenso acerca das medidas que precisam ser tomadas), implicam a assunção de um papel que os magistrados não estão acostumados a desempenhar e que pode interferir em sua autoridade ou independência no cenário político-institucional do local em que estão inseridos, além de suscitar as sempre presentes críticas acerca do controle jurisdicional de políticas públicas e do ativismo judicial.

\section{Referências}

ALMEIDA, Eloísa Machado de. Capacidades institucionais dos amici curiae no Supremo Tribunal Federal: acessibilidade, admissibilidade e influência. Revista Direito e Práxis, Rio de Janeiro, v. 10, n. 1, p. 678-707, 2019. Disponível em: https://www.e-publicacoes.uerj.br/index.php/revistaceaju/article/view/39502. Acesso em: 19 abr. 2020.

ARAÚJO, Ana Valéria. Fortalecer a sociedade civil significa também empoderá-la para a defesa de seus direitos. In: ARAÚJO, Ana Valéria et al. Litigância estratégica em direitos humanos: experiências e reflexões. São Paulo: Escola de Direito da FGV, 2016. p. 8-10.

ARENHART, Sérgio Cruz. Decisões estruturais no direito processual civil brasileiro. Revista de Processo, São Paulo, v. 225, n.75, p. 389-410, 2013.

BARROSO, Luís Roberto. Constituição, democracia e supremacia judicial: direito e política no Brasil contemporâneo. Revista Jurídica da Presidência, Brasília, v. 12, n. 96, p. 05-43, 2010. Disponível em: https:// revistajuridica.presidencia.gov.br/index.php/saj/article/view/230. Acesso em: 20 abr. 2020.

BRINKS, Daniel; GAURI, Varun. Sobre triángulos y diálogos: nuevos paradigmas em la intervención judicial sobre el derecho a la salud. In: GARGARELLA, Roberto (org.). Por una justicia dialógica: el poder judicial como promotor de la deliberación democrática. Buenos Aires: Siglo Veintiuno, 2014. p. 293-320.

BRINKS, Daniel M.; FORBATH, William. Social and economic rights in Latin America: Constitutional Courts and the prospects for pro-poor interventions. Texas Law Review, Texas, v. 89, n.7, p.1993-1954, 2010. Disponível em: https://repositories.lib.utexas.edu/handle/2152/22488. Acesso em: 19 abr. 2020.

CABALLERO, Jackeline Saravia; FERNÁNDEZ, Andrea Rodríguez. Los desplazados forzados internos en el estado de cosas inconstitucional, un asunto pendiente. Prolegómenos Derechos y Valores, Bogotá, v. 18, n. 35, p. 121-134, enero/jun. 2015. Disponível em: https://www.redalyc.org/pdf/876/87638077007.pdf. Acesso em: 02 mar. 2020.

CAMPOS, Carlos Alexandre de Azevedo. Estado de coisas inconstitucional. Salvador: Juspodium, 2016.

CARDOSO, Evorah. Ciclo de vida do litígio estratégico no sistema interamericano de direitos humanos: dificuldades e oportunidades para atores não estatais. Revista Electrónica del Instituto de Investigaciones Ambrosio L. Gioja, Buenos Aires, ano 5, n. Especial, p. 363-378, 2011. Disponível em: http://bibliotecavirtual. cebrap.org.br/arquivos/272_artigo.pdf. Acesso em: 23 mar. 2020.

CARVALHO, Sandra; BAKER, Eduardo. Experiências de litígio estratégico no Sistema Interamericano de Proteção dos Direitos Humanos. Revista Internacional de Direitos Humanos, São Paulo, v. 11, n. 20, p. 465-475, jun./dez. 2014. Disponível em: https://sur.conectas.org/wp-content/uploads/2017/11/sur20-pt-sandracarvalho-eduardo-baker.pdf. Acesso em: 1 fev. 2020. 
DALLA, Humberto; CÔRTES, Victor Augusto Passos Villani. As medidas estruturantes e a efetividade das decisões judiciais no ordenamento jurídico brasileiro. Revista Eletrônica de Direito Processual, Rio de Janeiro, v. 13, n. 13, p. 229-258, 2014. Disponível em: https://www.e-publicacoes.uerj.br/index.php/redp/article/ view/11920/9333. Acesso em: 23 mar. 2020.

DANTAS, Eduardo Sousa. Ações estruturais, direitos fundamentais e o estado de coisas inconstitucional. Revista Digital Constituição e Garantia de Direitos, Natal, v. 9, n. 2, p. 155-176, 2016. Disponível em: https:// periodicos.ufrn.br/constituicaoegarantiadedireitos/article/view/12258. Acesso em: 15 mar. 2020.

DÍAZ, Ana Milena Coral; TORO, Beatriz Londoño; ÁVILA, Lina Marcela Muñoz. El concepto de litigio estratégico en América Latina: 1990-2010. Vniversitas, Bogotá, v. 59, n. 121, p. 49-76, 2010. Disponível em: https:// revistas.javeriana.edu.co/index.php/vnijuri/article/view/14413. Acesso em: 12 mar. 2020.

Duque, César. ¿Por qué un litigio estratégico en derechos humanos?. Aportes Andinos, Quito, n. 35, p. 9-23, dic. 2014. Disponível em: https://repositorio.uasb.edu.ec/handle/10644/4430. Acesso em: 13 de mar. 2020.

DORA, Ana Denise. A agenda de direitos humanos transforma a pirâmide de privilégios e exclusões. In: ARAÚJO, Ana Valéria et al. Litigância estratégica em direitos humanos: experiências e reflexões. São Paulo: Escola de Direito da FGV, 2016. p.11-14.

FACHIN, Melina Girardi; SCHINEMANN, Caio Cesar Bueno. Decisões estruturantes na jurisdição constitucional brasileira: critérios processuais da tutela jurisdicional de direitos prestacionais. Revista de Estudos

Institucionais, Rio de Janeiro, v. 4, n. 1, p. 211-246, 2018. Disponível em: https://estudosinstitucionais.com/REI/ article/view/247. Acesso em: 21 abr. 2020.

FFISHER, Louis. Constitutional dialogues: interpretation as political process. Princeton: Princeton University Press, 1988.

FISS, Owen. The forms of justice. Harvard Law Review, Cambridge, v. 93, n.1, p. 1-58, 1979. Disponível em: https://digitalcommons.law.yale.edu/cgi/viewcontent.cgi?article=2201\&context=fss_papers. Acesso em: 19 abr. 2020.

COLLUCCI, Cláudia. Doentes graves ganham na justiça, mas remédios caros travam no SUS. Folha de São Paulo, São Paulo, 16 jul. 2017. Disponível em: https://www1.folha.uol.com.br/cotidiano/2017/07/1901633doentes-graves-ganham-na-justica-mas-remedios-caros-travam-no-sus.shtml. Acesso em: 20 jun. 2020.

FONTE, Felipe de Melo. Políticas públicas e direitos fundamentais. Rio de Janeiro: Saraiva, 2017.

GRAZIADEI, Michele. Comparative Law as the study of transplants and receptions. In: REIMANN, Mathias; ZIMMERMANN, Reinhard (ed.). The Oxford handbook of comparative law. Cambridge: Oxford University Press, 2019. p.440-474.

JOBIM, Marcos Félix; ROCHA, Marcelo Hugo. Medidas estruturantes: origem em Brown v. Board of Education. In: ARENHART, Sérgio Cruz; JOBIM, Marco Félix (org.). Processos estruturais. Salvador: JusPodivm, 2017. p.563-582.

MCCANN, Michael W. Rights at work: pay equity reform and the politics of legal mobilization. Chicago: University of Chicago Press, 1994.

MITIDIERO, Daniel. O processualismo e a formação do Código Buzaid. Revista de Processo, São Paulo, v. 183, n.183, 165-194, 2010.

MÜLLER-CHEN, Markus et al. Annex: guidelines for writing a paper in comparative private law. In: CHENMULLER, Markus; MULLER, Christoph; LUCHINGER, Corinne (org.). Comparative private law. Suíça: Dike, 2015. p. 425-433.

NÓBREGA, Flavianne Fernanda Bitencourt. Um método para a investigação das consequências: a lógica pragmática da abdução de CS Peirce aplicada ao direito. João Pessoa: Ideia, 2013. 
OSORIO, Leticia Marques. Litígio estratégico em direitos humanos: desafios e oportunidades para organizações litigantes. Revista Direito e Práxis, Rio de Janeiro, v. 10, n.1, p. 571-592, 2019. Disponível em: https://www.epublicacoes.uerj.br/index.php/revistaceaju/article/view/39377. Acesso em: 20 abr. 2020.

PEIRCE, Charles S. How to make our ideas clear. In: WEINER, Philip P. Charles S. Peirce: selected writings. New York: Dover, 1966. p.1-20.

PEIRCE, Charles S. Pragmatismo e abdução. In: PEIRCE, Charles S. Semiótica. São Paulo: Perspectiva, 2003. p. 230-255.

$\mathrm{ROACH}$, Kent. The challenges of crafting remedies for violations of socio-economic rights. Harvard Law Review, Cambridge, v. 89, n.1, p. 1281-1316, 1976.

RODRÍGUEZ GARAVITO, César et al. El activismo dialógico y el impacto de los fallos sobre derechos sociales. Revista Argentina de Teoría Jurídica, Buenos Aires, v. 14, n. 2, p. 1-27, dez. 2016.

RODRÍGUEZ-GARAVITO, César A.; FRANCO, Diana Rodríguez. Cortes y cambio social: cómo la Corte Constitucional transformó el desplazamiento forzado en Colombia. Bogotá: Dejusticia, 2010.

SHAPIRO, David L. Some thoughts on intervention before courts, agencies and arbitrators. Harvard Law Review, Cambridge, v. 81, n. 4, p. 721-737, fev. 1968.

VALLE, Vanice Lírio do. Estado de coisas inconstitucional e bloqueios institucionais: desafios para a construção da resposta adequada. In: BOLONHA, Carlos; BONIZZATO, Luigi; MAIA, Fabiana (org.). Teoria institucional e constitucionalismo contemporâneo. Curitiba: Juruá, 2016. p.1-28.

VENTURI, Elton. Processo civil coletivo: a tutela jurisdicional dos direitos difusos, coletivos e individuais homogêneos no Brasil: perspectivas de um Código Brasileiro de Processos Coletivos. São Paulo: Malheiros Editores, 2007.

VITORELLI, Edilson. Levando os conceitos a sério: processo estrutural, processo coletivo, processo estratégico e suas diferenças. Revista de Processo, São Paulo, v. 284, n. 28, p. 333-369, jan. 2018.

WEAVER, Russell L. The rise and decline of structural remedies. San Diego Law Review, San Diego, v. 41, n.1, p. 1617-1650, 2004. Disponível em: https://digital.sandiego.edu/sdlr/vol41/iss4/11/. Acesso em: 12 abr. 2020.

ZWEIGERT, Konrad; KÖTZ, Hein. Introduction to comparative law. Oxford: Oxford University Press, 1992.

Recebido em: 05.08.2020

Aceito em: 20.09.2021 